\title{
PENGARUH TEMBAGA(II) DAN KADMIUM(II) TERHADAP PERSEN EKSTRAKSI MERKURI(II) MENGGUNAKAN EMULSI MEMBRAN CAIR TIPE W/O BERSURFAKTAN GANDA DENGAN BENZOIL ASETON SEBAGAI PEMBAWA KATION
}

\section{THE EFFECT OF COPPER (II) AND CADMIUM (II) ON MERCURY (II) EXTRACTION PERCENT USING LIQUID MEMBRANE EMULSION TYPE W/O DOUBLE SURFACTANT WITH BENZOYL ACETONE AS CATION BEARER}

\author{
Baharuddin Hamzah*, Husnia Muchtar, Sitti Rahmawati \\ Program Studi Pendidikan Kimia, Jurusan Pendidikan MIPA \\ Fakultas Keguruan dan Ilmu Pendidikan - Universitas Tadulako \\ *Corresponding Author: talimbangan@gmail.com
}

Submit : 15 Oktober 2017 Accepted : 06 November 2017

\begin{abstract}
A study of the effect of copper (II) and cadmium (II) on mercury (II) extraction percent using a fluorescent $\mathrm{w} / \mathrm{o}$ liquid membrane emulsion with benzoyl acetone as a cation carrier was used. The optimum conditions used in this study are as follows. The emulsion was made using a mixture of surfactant span-80 \& span-20 $=2 \%$, emulsification rate $=2000 \mathrm{rpm}$ for $10 \mathrm{~min}$, internal phase membrane phase $/$ phase ratio $=1$, $\mathrm{HNO} 3$ concentration in internal phase $=2 \mathrm{M}$. Extraction was performed on $30 \mathrm{ppm}$ mercury as external phase with $\mathrm{pH}=2$ and extraction rate $300 \mathrm{rpm}$ for $10 \mathrm{~min}$ and the ratio of phase volume of external $/$ emulsion $=7$, The result showed that mercury extraction (II) with liquid membrane emulsion, relatively selective to copper (II) and cadmium (II). The results also showed that the presence of copper (II) and cadmium (II) to $30 \mathrm{ppm}$, decreased mercury (II) percentage of $12.12 \%$ and $11.74 \%$, respectively.
\end{abstract}

Keywords:Mercury (II), Copper (II), Cadmium (II), Liquid membrane emulsion

\section{PENDAHULUAN}

Untuk meningkatkan taraf hidup serta kesejahteraan masyarakat, berbagai usaha telah dilakukan pemerintah pada akhir-akhir ini. Salah satu usaha yang sedang digalakkan adalah ditingkatkannya sektor industri baik yang berupa industri berat maupun industri ringan. Namun dengan munculnya industri perlu dipikirkan juga efek sampingnya berupa limbah. Salah satu jenis limbah yang cukup berbahaya adalah logam berat, baik dalam bentuk larutan, padatan maupun gas.

Merkuri adalah salahsatu logam berat berbahaya dan secara alami kelimpahannya di alam sangatlah sedikit. Namun kelimpahan ini dapat menjadi lebih banyak di lingkungan karena adanya aktivitas manusia yang menghasilkan limbah cair merkuri seiring dengan kemajuan teknologi dan pertambahan jumlah penduduk [1] dan saat ini merkuri telah banyak digunakan dalam dunia industri modern. [2]

Banyak tehnik pengolahan limbah cair industri yang dapat diaplikasikan, namun perlu juga difikirkan metode perolehan kembali (recovery) logam berat tersebut agar dapat dimanfaatkan kembali untuk industri lainnya. Tehnik pengolahan limbah cair seperti pengendapan dan penyaringan selalu menghasilkan limbah padat yang membutuhkan proses pengolahan kembali, dimana proses ini membutuhkan pereaksi secara berlebihan yang pada akhirnya akan menjadi pencemar yang baru. [3] Tehnik pengolahan lain yang dapat dilakukan adalah ekstraksi pelarut, namun cara ini kurang efisien dan kurang ekonomis karena tahap ekstraksi dan ekstraksi balik dilakukan berulang kali. Tehnik pemisahan yang masih berkembang hingga kini adalah tehnik emulsi membran cair. Tehnik ini memberikan jangkauan aplikasi yang luas dan potensial karena karakteristiknya seperti kemudahan dalam pengoperasiannya, biaya operasional yang relatif lebih murah, keselektifan tinggi dan efisien (tahap ekstraksi dan ekstraksi balik terjadi dalam satu tahap). [4] 
Tehnik emulsi membran cair telah banyak diaplikasikan untuk beberapa penelitian, misalnya ekstraksi logam kadmium. [5, 6] tembaga. [7, 8, 9, $10,11]$ timbal $[12,13,14,15,16,17,18]$, kromium [19], kobal [20, 21], arsen [22], ekstraksi dan pemisahan Penisilin G [23] .

Emulsi membran cair dibuat dengan membentuk emulsi dari dua fasa cair yang tidak saling campur dan untuk menstabilkan emulsi selama proses ekstraksi ditambahkan surfaktan yang berfungsi untuk menurunkan tegangan permukaan, kemudian emulsi yang terbentuk didispersikan ke fasa eksternal. Penggunaan surfaktan campuran span-80 dan span-20 dimaksudkan agar nilai HLB surfaktan sesuai atau sama dengan nilai HLB butuh dari kerosen sehingga akan diperoleh emulsi yang stabil. Fasa eksternal mengandung ion merkuri yang akan diekstraksi sedangkan fasa internal merupakan fasa penerima ion merkuri setelah melewati fasa membran . Mekanisme ekstraksi diawali dengan adanya reaksi pada permukaan luar membran antara ion merkuri dengan ekstraktan benzoil aseton sebagai pembawa kation (yang terlarut dalam fasa membran), membentuk kompleks $\mathrm{Hg}$ (benzoilaseton $)_{2}$ yang larut baik dalam fasa membran. Kompleks ini berdifusi di dalam fasa membran menuju fasa internal. Oleh karena adanya zat pembebas di dalam fasa internal $\left(\mathrm{HNO}_{3}\right)$ maka ion merkuri akan dilepaskan dari senyawa kompleksnya pada permukaan dalam membran dan akan terlarut ke dalam fasa internal. Selanjutnya zat pembawa kation benzoil aseton yang telah melepaskan ion merkuri tersebut akan berdifusi kembali ke permukaan luar membran untuk membentuk kompleks yang baru dengan ion merkuri lainnya.

Beberapa penelitian terdahulu tentang ekstraksi merkuri(II) telah dilakukan [24, 25, 26]. Namun perlu juga diketahui bahwa keberadaan merkuri(II) di alam atau dalam suatu limbah selalu bersama ion-ion logam lainnya. Oleh karena itu dalam penelitian ini telah dipelajari pengaruh beberapa ion logam (tembaga dan kadmium) pada ekstraksi merkuri(II) menggunakan emulsi membran cair.

\section{METODE PENELITIAN}

\section{Alat}

Peralatan gelas laboratorium, neraca digital

(AND GR-200), pH meter (Lamotte), Spektrofotometer UV-Vis (Perkin Elmer Lamda 25), emulsification / agitation stirer $(0-3000$ rpm).

\section{Bahan}

Semua bahan yang digunakan berkualitas p.a (Merck) yaitu : merkuri klorida, benzoil aseton,, asam nitrat, span-20, span-80, dodekana/kerosen, ditizone, karbon tetra klorida, air suling, tembaga nitrat, kadmium nitrat.

\section{Prosedur Kerja}

1. Emulsi dibuat dengan jalan mencampurkan fasa membran (larutan 0,02M benzoil aseton dan $2 \%$ surfaktan campuran span-80 \& span20 dalam pelarut kerosen) dengan fasa internal (larutan HNO3 2M dalam air) dengan perbandingan volume sama banyak. Kemudian diaduk dengan kecepatan emulsifikasi 2000 rpm selama 10 menit.

2. Ekstraksi dilakukan dengan mencampurkan 30 $\mathrm{mL}$ emulsi dengan $150 \mathrm{~mL}$ fasa eksternal pada $\mathrm{pH}=2$ (campuran $75 \mathrm{~mL}$ larutan merkuri(II) $60 \mathrm{ppm}$ dengan $75 \mathrm{~mL}$ larutan $\mathrm{Cu}(\mathrm{II})$ dan atau $\mathrm{Cd}(\mathrm{II})$ dengan konsentrasi bervariasi $20 \mathrm{ppm}$, 40 ppm, 60 ppm, 80 ppm dan 100 ppm.). kemudian diaduk dengan kecepatan 300 rpm selama 10 menit.

3. Konsentrasi merkuri(II) yang tersisa pada fasa eksternal setelah ekstraksi ditentukan dengan Spektrofotometer Sinar Tampak pada panjang gelombang $490 \mathrm{~nm}$, menggunakan larutan ditizon $0,001 \%$ sebagai pengkompleks.

\section{HASIL DAN PEMBAHASAN \\ Pengaruh $\mathrm{Cu}(\mathrm{II})$ terhadap persen ekstraksi Hg(II)}

Berdasarkan hasil percobaan dan perhitungan, diperoleh kurva hubungan konsentrasi $\mathrm{Cu}(\mathrm{II})$ terhadap persen ekstraksi $\mathrm{Hg}$ (II) dan terhadap persen ekstraksi $\mathrm{Cu}$ (II) seperti pada Gambar. 1

Percobaan ini bertujuan untuk mengetahui pengaruh $\mathrm{Cu}$ (II) terhadap persen ekstraksi $\mathrm{Hg}$ (II) yang dilakukan dengan jalan mengekstraksi $\mathrm{Hg}$ (II) 30 ppm dalam campurannya dengan $\mathrm{Cu}$ (II) 0 - 30 ppm. Kurva pada Gambar 1 menunjukkan bahwa dengan penambahan konsentrasi $\mathrm{Cu}$ (II) 0 30 ppm ternyata dapat menurunkan persen ekstraksi $\mathrm{Hg}$ (II) sebesar $12,12 \%$. Kurva pada Gambar 1 juga memperlihatkan bahwa ekstraksi $\mathrm{Hg}$ (II) dengan menggunakan kondisi optimum ekstraksi $\mathrm{Hg}$ (II) relatif selektif terhadap $\mathrm{Cu}(\mathrm{II})$. Hal ini ditunjukkan dengan relatif sedikitnya $\mathrm{Cu}(\mathrm{II})$ yang ikut terekstraksi (\% $\mathrm{E}=5,90)$. 


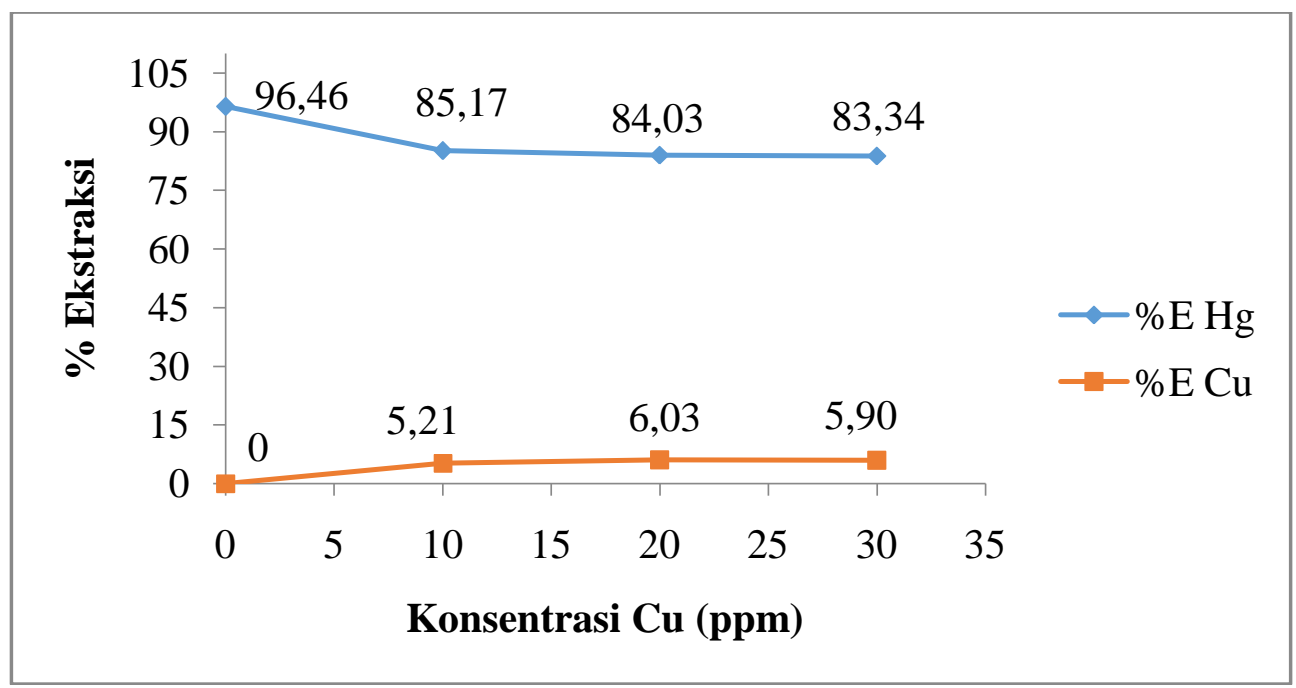

Gambar 1. Kurva hubungan konsentrasi $\mathrm{Cu}$ (II) terhadap persen ekstraksi $\mathrm{Hg}$ (II) dan terhadap persen ekstraksi $\mathrm{Cu}(\mathrm{II})$

\section{Pengaruh Cd(II) terhadap persen ekstraksi} Hg(II)

Berdasarkan hasil percobaan dan perhitungan, diperoleh kurva hubungan konsentrasi $\mathrm{Cd}(\mathrm{II})$ terhadap persen ekstraksi $\mathrm{Hg}$ (II) dan terhadap persen ekstraksi Cd(II) seperti pada Gambar. 2.

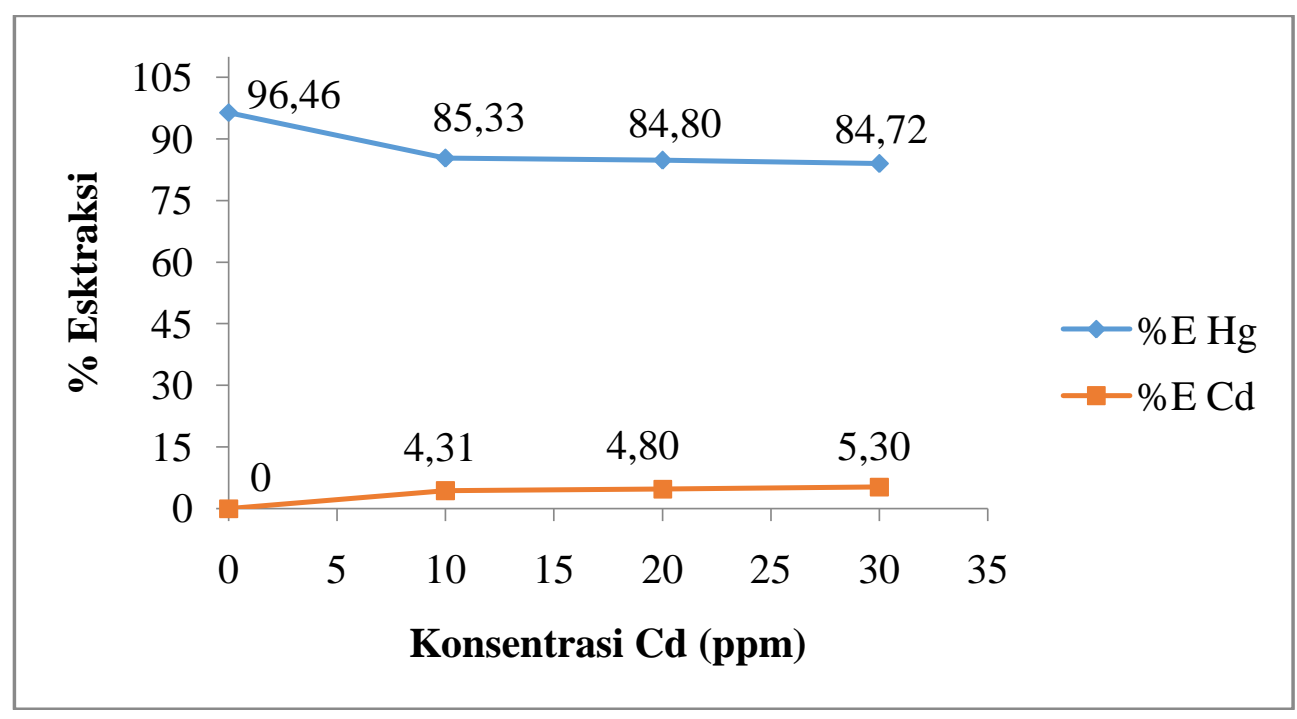

Gambar 2. Kurva hubungan konsentrasi $\mathrm{Cd}(\mathrm{II})$ terhadap persen ekstraksi $\mathrm{Hg}$ (II) dan terhadap persen ekstraksi Cd(II)

Percobaan ini bertujuan untuk mengetahui pengaruh $\mathrm{Cd}(\mathrm{II})$ terhadap persen ekstraksi $\mathrm{Hg}$ (II) yang dilakukan dengan jalan mengekstraksi $\mathrm{Hg}$ (II) 30 ppm dalam campurannya dengan $\mathrm{Cd}(\mathrm{II})$ 0 - 30 ppm. Kurva pada Gambar 2 menunjukkan bahwa dengan penambahan konsentrasi Cd(II) 0 30 ppm ternyata dapat menurunkan persen ekstraksi $\mathrm{Hg}(\mathrm{II})$ sebesar $11,74 \%$. Kurva pada Gambar 2 juga memperlihatkan bahwa ekstraksi
$\mathrm{Hg}(\mathrm{II})$ dengan menggunakan kondisi optimum ekstraksi $\mathrm{Hg}(\mathrm{II})$ relatif selektif terhadap Cd(II). Hal ini ditunjukkan dengan relatif sedikitnya $\mathrm{Cd}(\mathrm{II})$ yang ikut terekstraksi (\% $\mathrm{E}=5,30)$.

Gambar 1 dan Gambar 2 menunjukkan bahwa keberadaan $\mathrm{Cu}(\mathrm{II})$ lebih banyak menurunkan persen ekstraksi $\mathrm{Hg}$ (II) dibandingkan $\mathrm{Cd}(\mathrm{II})$. Hal ini disebabkan karena dalam penggolongan asam basa menurut teori HSAB 
(Hard Soft Acid Base) Cu(II) termasuk dalam golongan asam madya sedangkan $\mathrm{Cd}$ (II) termasuk golongan asam lunak. Akibatnya $\mathrm{Cu}(\mathrm{II})$ lebih cenderung tertarik oleh ligan benzoil aseton yang dapat digolongkan sebagai basa keras, sehingga $\mathrm{Cu}$ (II) lebih banyak mempengaruhi penurunan persen ekstraksi $\mathrm{Hg}(\mathrm{II})$. Hal ini juga didukung oleh hasil percobaan yang menunjukkan bahwa $\mathrm{Cu}$ (II) lebih banyak ikut terekstraksi $(5,90 \%)$ dibandingkan $\mathrm{Cd}(\mathrm{II})(5,30 \%)$.

\section{KESIMPULAN}

1. Ekstraksi merkuri(II) dengan emulsi membran cair, relatif selektif terhadap tembaga(II) dan kadmium(II).

2. Keberadaan tembaga(II) dan kadmium(II) hingga $30 \mathrm{ppm}$, menurunkan persen ekstraksi merkuri(II) $30 \mathrm{ppm}$ berturut-turut 12,12\% dan $11,74 \%$.

\section{DAFTAR PUSTAKA}

[1]. Purnawan, S., Sikanna, R., Prismawiyanti. 2003. Online Jurnal of Natural Science, 2(1), 18-24.

[2]. Rimjhim, J., Kumar, S.S., Uma, A., Saurabh, K., Neha, S. 2013. International Research Journal of Pharmacy, 4(8), 38-41

[3]. Chakravati, A.K., Chowdhdury, S.B., Mukherjee, D.C., 2000. Colloids and Surfaces, A physiochemical and engineering aspects, 166(1-3), 7-25.

[4]. Gawronski, R., Religa, P., 2007. Journal of Membrane Science, 289(1-2), 187-190.

[5]. Ahmad, A.L., Buddin, S.M.M.H., Ooi, B.S., Kusumastuti,A., 2017, Journal of Water Process Engineering 16 : 26-30.

[6]. Sanjaya, R. (2011). Ekstraksi ion Cd(II) menggunakan membran cair emulsi bersurfaktan span-80 dengan ekstran 1fenil-3-metil-4-benzoil-5-pirazolon. Skripsi pada FMIPA Univeristas Hasanuddin, Makassar.

[7]. Hamzah, B., Jalaluddin, N., Wahab, AW, Upe, A., 2011, Natur Indonesia, 13 (3), 269-275.

[8]. Hamzah, B., Said,I., Hardani,R., 2013A, J.Akad.Kim. 2(3): 114-118.

[9]. Hamzah, B., Tuljannah,N., Diharnaini, 2013B, J.Akad.Kim. 2(2): 76-81.

[10]. Lu, D., Chang, Y., Wang, W., Xie, F., Asselin, E., Dreisinger, D., 2015, Metals 5 : 2034-2047.

[11]. Bi, Q., Xue, J.Q., Guo, Y.J., Li, Cui,H., 2016, Water Science \& Technology 75(3).
[12]. Gurel, L., Altas, L., Buyukgungor, H., 2005. Environmental EngineeringScience, 22 (4), 411-420.

[13]. Lende,A.B., Dinder,M.K., Bhosale,V.K., Kamble,S.P., Meshram,P.D., Kulkami,P.S., 2014, Royal Society of Chemistry Issue 94.

[14]. Hamzah, B., Alam,S., Nuryanti,S., Nurbaya,S., 2014A, J.Akad.Kim. 3(2): 329335.

[15]. Hamzah, B., Astuti,W., Suherman, Laonu,S.R., 2015, J.Akad.Kim. 4(2): 104109.

[16]. Hamzah, B., Djasman,S.M., Walanda,D.K., Husnia, 2014B, J.Akad.Kim. 3(4): 417-422.

[17]. Irawati, A, D., 2015, Pengaruh ion logam $\mathrm{Cu}(\mathrm{II})$ terhadap persen ekstraksi ion timbal(II) menggunakan teknik emulsi membran cair. Skripsi Sarjaana FKIP Universitas Tadulako Palu.

[18]. Setyani, R., Hamzah, B., Suherman, 2016, J.Akad.Kim. 5(2): 91-97.

[19]. Chiha, M., Samar, MH, Hamdaoni, O., 2006. Desalination 194 (2), 69-80.

[20]. Kassem,A.T., El-said,N., Aly,H.F, 2013, IOSR Journal og Applied Chemistry 6(4):45-52.

[21]. Hachemaoni, A., Belhamel, K., 2017, International Journal of Mineral Processing.

[22]. Marino, T., Figoli, A., 2015, Membranes 5 : 150-167.

[23]. Santoso, I, Buchari, Amran, M.B, Sulaiman, A. 2007. Jurnal of Mathematics and Science, 12 (3), 94-101.

[24]. Sulniawati, 2016. Ekstraksi Ion Merkuri Menggunakan Teknik Emulsi Membran Cair dengan Variasi Konsentrasi Benzoil Aseton dalam Fasa Membran dan Variasi $\mathrm{pH}$ fasa Eksternal. Skripsi Sarjana pada FKIP Universitas Tadulako Palu.

[25]. Tangdikanan, F.G.,2016. Penentuan Perbandingan Volume Fasa Membran dan Volume Fasa Internal serta Lama Waktu Ekstraksi pada Proses Ekstraksi Ion Merkuri Menggunakan Teknik Emulsi Membran Cair. Skripsi Sarjana pada FKIP Universitas Tadulako Palu.

[26]. Supriyatno, T.O. 2016, Penentuan Kondisi Optimum (Konsentrasi $\mathrm{HCl}$ dan Konsentrasi Ion Merkuri) Pada Ekstraksi Ion Merkuri Menggunakan Teknik Emulsi Membran Cair. Skripsi Sarjana pada FKIP Universitas Tadulako Palu. 